\title{
Calliphora vicina human myiasis: a case report
}

\author{
Massimo Salvetti · Claudia Corbellini • \\ Carlo Aggiusti • Enrico Agabiti Rosei • \\ Maria Lorenza Muiesan
}

Received: 25 August 2011/Accepted: 15 October 2011/Published online: 2 November 2011

(C) SIMI 2011

\section{Introduction}

Calliphora vicina has been recorded from cases of myiasis, a parasitic disease where fly larvae are found feeding on the tissues of carrions or living mammals, usually of small size [1]. Myiasis cases involving C. vicina in living humans are extremely rare [1-4].

\section{Case report}

A 30-year-old man with a history of cocaine and alcohol abuse attempted suicide by jumping into a canyon in the afternoon of a warm day of summer 2011. He was found alive after $24 \mathrm{~h}$, with a contused and lacerated scalp wound, several hematomas and bruises all over the body.

At admission in the emergency department (ED), the patient was conscious and complained of headache and of pain throughout his entire body. Head, thorax and abdominal CT scans did not show any internal injuries or fractures. White blood cell count $\left(18.680 \mathrm{~mm}^{-3}\right)$, serum creatinine $(3 \mathrm{mg} / 100 \mathrm{ml})$, serum muscle enzymes (creatine phosphokinase $10,200 \mathrm{mU} / \mathrm{ml}$ ), creatine kinase isoenzyme MB $(26 \mathrm{mU} / \mathrm{ml})$ and troponin I were elevated $(0.61 \mathrm{ng} / \mathrm{ml})$. Electrolytes were normal and on the venous blood gases

Electronic supplementary material The online version of this article (doi:10.1007/s11739-011-0720-6) contains supplementary material, which is available to authorized users.

M. Salvetti - C. Corbellini - C. Aggiusti .

E. A. Rosei - M. L. Muiesan ( $₫)$

Clinica Medica, University of Brescia,

Spedali Civili Brescia, Brescia, Italy

e-mail: muiesan@med.unibs.it measurement, venous $\mathrm{CO}_{2}$ was slightly reduced and bicarbonate gap was slightly negative, possibly secondary to respiratory alkalosis compensation.

The electrocardiogram showed ST segment elevation with normal concavity in the inferior leads and no other signs of cardiac injury, including dysrhythmia or significant conduction delays. The echocardiogram was normal; in particular, the LV ejection fraction was normal $(68 \%)$ and no regional contractility abnormalities were observed.

A diagnosis of acute renal failure secondary to volume depletion and rhabdomyolysis was made, and the patient was then admitted to the internal medicine intensive care unit for vital parameters and ECG monitoring. The head wound was cleaned, medicated and sutured immediately after admission, in the late evening. The patient was treated by fluid infusion (saline $100 \mathrm{ml} / \mathrm{h}$ and sodium carbonate $40 \mathrm{ml} / \mathrm{h}$ ) and antibiotic therapy for possible bacterial infection (amoxicillin-clavulanic acid 3 g/day).

The next morning, the patient was quiet and had fewer complaints of pain, but still declaring suicidal ideation. The ECG ST-segment abnormalities had regressed. Serum creatinine was decreased, as well as CPK MB and troponin $\mathrm{I}$, and white cell count regressed to normal after $48 \mathrm{~h}$.

While dressing the head wound (about $12 \mathrm{~h}$ after the previous medication), a large amount of overgrowing maggots were seen (video and Figs. 1, 2 and 3). A sample of maggots was taken for microscopic examination, and a wound specimen for bacterial culture was also performed. At the microscopic examination, larvae of Calliphora vicina were identified, while the bacterial culture was negative.

No change to the current treatment was made. The patient was discharged with close psychiatric follow-up. 
Figs. 1-3 Overgrowing maggots, identified as larvae of Calliphora vicina, are observed on the patient's head wound
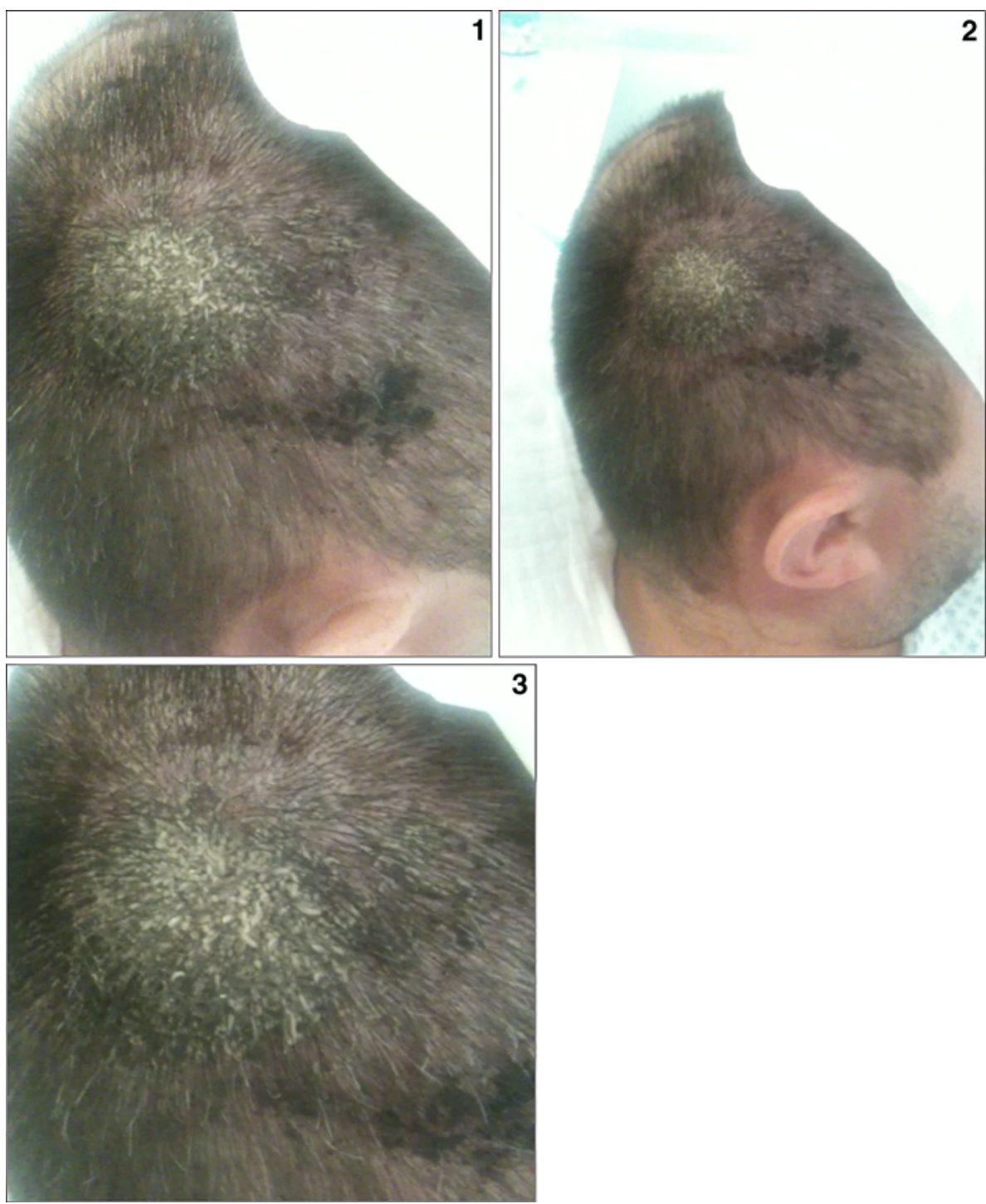

\section{Discussion}

Calliphora vicina is a very common urban species of fly, known as the bluebottle fly, because of the metallic blue-gray coloration of its thorax and abdomen. This fly is usually closely associated with man. Calliphora vicina is found predominantly in Europe, but also in the urban areas of the USA and most prevalent when the outdoor temperatures are around $13-24^{\circ} \mathrm{C}\left(55-75^{\circ} \mathrm{F}\right)$, mainly in spring and fall [1].

This fly has a lower threshold temperature for flight activity than other blowflies, and this allows a greater prevalence during colder periods. Climatic factors, such as temperature, are also known to influence egg laying and development of instar larvae. In warmer weather, the life cycle span is shorter, and in cooler temperatures the life cycle is longer.

The maggots feed on decaying organic matter, mainly animal carrion. Adult Calliphoridae females lay eggs on fresh cadavers immediately after death under favorable conditions. The ability of blowflies to locate and colonize corpses represents a key characteristic used in forensic investigations to estimate the postmortem interval. Knowing the duration between the three instars and pupa stage and post-feeding larval dispersal can be useful in the determination of a reasonable postmortem interval in a criminal case. In cases of advanced decomposition, when no tissues or body fluids are available, $C$. vicina and other Calliphoridae can serve as alternate specimens for toxicological analysis.

In the present case, the circumstances of the infestation are open to speculation. In some previous case reports, patients were both elderly and sick at the time of infection $[2,3]$, or were healthy with wounds associated with bacterial necrosis injury, determined by aerobic or anaerobic bacteria [4]. In our case, no bacteria could be isolated from the wound, and the patient was in good general health, 
other than his alcohol and cocaine addiction problems. The effects of codeine, morphine, paracetamol and diazepam, but not of cocaine, on larvae growth have been investigated and no differences in growth rate observed. We cannot exclude that during the night while the patient was lying in the canyon, the lower temperature may have favored the deposition of the fly and egg, while the maggots might have developed during nighttime while the patient was in hospital, at a much higher temperature. This can confirm that Calliphora vicina is indeed active at night in particular conditions, as recently shown [5].

This case confirms that myiasis is a potential complication of wound infection. Human myiasis usually occurs accidentally in neglected wounds and suppurating or necrotic tissue; species within the genera Cochliomyia and Chrysomya are the more common causative agents, while infection by Calliphora vicina is extremely rare. In case of myiasis infestation, no pre-hospital care is required. Larvae removal can be attained by the application of $15 \%$ chloroform in light vegetable oil, or $1 \%$ ether, under local anesthesia if necessary. Larvae can then be removed with forceps. The procedure can be performed in the ED or when the patient is admitted to the hospital. In some cases of eye and mouth myiasis, the use of topical application of ivermectin, a broad-spectrum antiparasitic, also indicated for the treatment of worm infestations, has been suggested. In the case of large wounds with necrotizing infections such as in the case reported by Dehlaes et al. [4], surgical debridement, with irrigation to eliminate the larvae from the wound, or surgical removal is needed.

Conflict of interest None.

\section{References}

1. Zumpt F (1965) Myiasis in man and animals in the old world. Butterworths, London

2. Granz W, Schneider D, Schumann H (1975) Human myiasis in middle Europe. Z Gesamte Inn Med 30:293-301

3. Ruiz Martinez I, Soler Cruz MD, Perez Jimenez JM, Diaz Lopez M, Sebastian Lazaro J (1992) Miasis cutanea semispecifica mixa. Rev Clin Esp 191:141-143

4. Dehlaes L, Bourel B, Scala L, Muanza B, Dutoit E, Wattel F, Gosset D, Camus D, Dei-Cas E (2001) Case report: recovery of Calliphora vicina first-instar larvae from a human traumatic wound associated with a progressive necrotizing bacterial infection. Am J Trop Med Hyg 64:159-161

5. Gennard D (2007) Forensic entomology: an introduction, Wiley, New York 